\title{
A Study on the Morphometric Asymmetry of Atlas Vertebrae
}

\author{
Mohd Salahuddin A (₫), Mukesh S, Binaya KB, Nilotpal C \\ Department of Anatomy, All India Institute of Medical Sciences, Rishikesh, 249203 Uttarakhand, India.
}

\begin{abstract}
The commonly used examination procedures of the upper cervical spine depend upon the symmetry for comparison and interpretation of joint functions. If symmetry is not normal, then these assessments may mislead the examiners, allowing them implementation of incorrect treatment plans. Objectives of this study are to explore the possibility that asymmetry is more common than symmetry and, if it is true, to find out the effects of asymmetry on the biomechanics of these joints. The study was carried out on 30 atlas vertebrae of cadavers of Indian origin. The different intra-atlas distances were measured on both sides by digital vernier calliper. All the parameters studied showed statistically significant differences between the right and left side i.e. a p value of $<0.05$. The anteroposterior diameter of the foramen transversarium, the transverse diameter of the foramen transversarium, the distance from the midline to medial edge of the vertebral artery groove (inner as well as outer cortex) and the length of the superior articular facets were more on the right side as compared to the left side. The breadth as well as the length of the inferior articular facet, the breadth of the superior articular facet and the difference of posterior arch thickness at the site of vertebral artery groove were more on the left side as compared to the right side. These differences may be explained by the handedness of an individual, which influences the intra-osteal asymmetry in a characteristically distinct manner, which needs to be confirmed or refuted in a further study.
\end{abstract}

Keywords: anatomy, asymmetry, biomechanics, cervical atlas, morphometry

\section{Correspondence:}

Mohd Salahuddin Ansari, Department of Anatomy, All India Institute of Medical Sciences, Rishikesh, 249203 Uttarakhand, India. Tel: +917500277776 Fax: 0135 2462941, Email: msalahuddin.ansari12@gmail.com

\section{Introduction}

Atlas and axis vertebrae have unique anatomical features compared to the rest of the cervical vertebrae. The greater range of motion of atlas than any other vertebrae of vertebral column makes it further special. Morphometric characterization of the atlas has been found to be useful in operative management of atlantoaxial complex and occipito-cervical instability $(1,2)$. The occiput, atlas and axis together they form a unique dynamic unit. These are connected to each other by articulations and /or by ligaments. Their biomechanical properties are also unique (3). The articulation between two occipital condyles and the corresponding two lateral masses of the atlas, between anterior arch of atlas and odontoid process of axis and between the two inferior articular facets of atlas and corresponding two superior articular facets of axis are of hinge, pivot and plane variety of synovial joint respectively. Though there is no direct bony articulation between the occiput and axis but they are connected to each other by alar and apical ligaments from the odontoid process of axis. Atlas was chosen for this study because of its central position in this dynamic unit.

The commonly used examination procedures of the upper cervical spine involve gross range of movements, static palpation and motion palpation. Examination of joint has been historically dependent upon symmetry for comparison and interpretation of joint function. If symmetry is not a normal finding, then range of motion and palpation assessments may mislead the examiner and thus cause the implementation of incorrect treatment plans. So, there may be compounding of the problem because gross range of motion gives no information about inter-segmental movements. 
Furthermore, there is an inherent lack of interexaminer reliability (4) with some motion palpation assessments.

Most of the surgical theories and techniques consider the atlas to be a source or contributing factor to many pathologies, including cervicogenic headaches, disequilibrium, and otalgia when the biomechanics of the atlanto-occipital and /or atlanto-axial joints are disturbed (3). Fitz-Ritson reported a high correspondence of upper cervical joint fixations in patients suffering from cervicogenic vertigo (5). Literature also reveals that the occipito-atlantal joints are responsible for about one half of all cervical flexion and extension (6).

Ranges of inter-segmental cervical motions observed by different workers are different. Because of lack of a statistical average or normal, these differences confound the examination of the joints. Based on these differences, it is very difficult to deny the possibility of asymmetry of joints among individuals. The movement of occipital condyles over the atlas produces $10^{\circ}$ of flexion, $15^{\circ}$ of extension and about $7^{\circ}$ of lateral bending (6). Some authorities deny the occurrence of rotation between occipital condyles and atlas, however, Schafer and Faye estimated it to be $3^{\circ}$ (6). This suggests anatomical differences among individuals rather than the reference source being right or wrong. The possibility of small amount of passive rotation between mastoid process of the occiput and the transverse process of atlas, on passive testing, has been reported by some workers (7). Isolated movements are quite difficult to isolate because there is coupling of axis with the movement of atlas.

Symmetrical functions are possible only in the presence of symmetrical anatomical structures. Because of the non- existence of the true structural symmetry, true symmetry of segmental movement is not possible (8). Usually the superior articular facets of the atlas are described as smooth, slightly concave, oval or kidneyshaped surfaces on top of the lateral masses of the atlas which is actually found in very few of the cases. Most of the facet outlines are irregular, resulting in various shapes. There is variation of shape among atlases as well as between the two sides of the same atlas. Usually, the constriction in the middle of the superior articular facet renders its shape to figure of eight or dumbbell shape (9). During a study of 200 atlases, Singh et al found variations in the constriction of the superior articular facet at different locations like lateral, medial and as well as on both sides of superior articular facet. Within the rough superior surface of the facet, smoother circular areas were noted (9) within the outline of the facet. Probably the circular areas represent pressure areas during the movement and rough areas represent the non-articular areas. In general, human beings during their day to day activities tend to incline their heads to one side more than the other and that may influence the amount of articular surface area on each side of the atlas as well as on the occipital condyles (10). Few workers discussed the complete division of superior articular facets and variation in the depth of intact facets from being flat, $3 \mathrm{~mm}$ or less to $5 \mathrm{~mm}$ or greater (11). The magnitude of the flexion and extension possible between the atlas and occipital condyles is influenced by the depth of the superior articular facets of the atlas. Furthermore, a project exploring the morphological asymmetry of atlas by comparing multiple structural variables bilaterally revealed that vertebral canal width and the morphology of the superior and inferior articular facets showed significant asymmetry (1). So, it seems that asymmetry of the cranio-vertebral bony and a ligamentous structure is almost the rule rather than the exception (8).

For a comprehensive understanding of asymmetry of atlas, a brief description of occiput is also needed because of its reciprocal relation with atlas. There are six ossification centres for occipital bone from which it develops. The articular surfaces of the occipital condyles in the new-born and infants are having a solelike configuration and are subdivided by a deep cleft (12). In computer assisted radiographic study of asymmetry was unequivocal finding which suggests the greater variability in the occipital condyles against the common assumption $(13,14)$. Morphological asymmetry between the atlas and occiput predicts that there must be asymmetry in the movements between these two bones because the morphological differences cannot be nullified $(15,16)$. Apart from the asymmetry between the articular surfaces of atlas and occipital condyles being common, there are certain references, though scanty in number, stating about the intra-atlas asymmetries $(2,17,18,19)$. Hence, the purpose of the present study was to explore the possibility that asymmetry is more common than the symmetry and, if it is true, to find out the magnitude and statistical significance of intra-atlas asymmetry and to discuss the effects of asymmetry on the biomechanics and the methods used to evaluate these joints, if any.

\section{Materials and Methods}

We conducted the study on 30 adult atlas vertebrae in the anatomy department in a medical college in northern India. No identifiable patient information about the vertebrae was available. Multiple parameters were measured on both the right and left side (Table 1). Pictorial representations of the various measurements are shown in Figures 1, 2 and 3. All distances were measured by digital vernier calliper, accurate to $0.1 \mathrm{~mm}$ 
for linear measurements. The statistical properties of the measured parameters and the paired differences between the right and left-sided parameters were examined by univariate statistics as well as graphically by boxplots. Since the paired differences of a few parameters showed a significant departure from normality, the non-parametric Wilcoxon Signed Rank

Table 1: The anatomical parameters of interest in this study. Measurement of each parameter was done on both the right and left sides.

\begin{tabular}{ll}
\hline No & \multicolumn{1}{c}{ Parameter } \\
\hline 1 & $\begin{array}{l}\text { Distance from midline to medial most edge of vertebral } \\
\text { artery groove outer cortex }\end{array}$ \\
2 & $\begin{array}{l}\text { Distance from midline to medial most edge of vertebral } \\
\text { artery groove on inner cortex }\end{array}$ \\
3 & Superior articular facet-length \\
4 & Superior articular facet-Breadth \\
5 & Inferior articular facet-length \\
6 & Inferior articular facet-Breadth \\
7 & Thickness of vertebral artery groove \\
8 & Foramen transversarium Anterior posterior diameter \\
9 & Foramen transversarium Transverse diameter \\
\hline
\end{tabular}

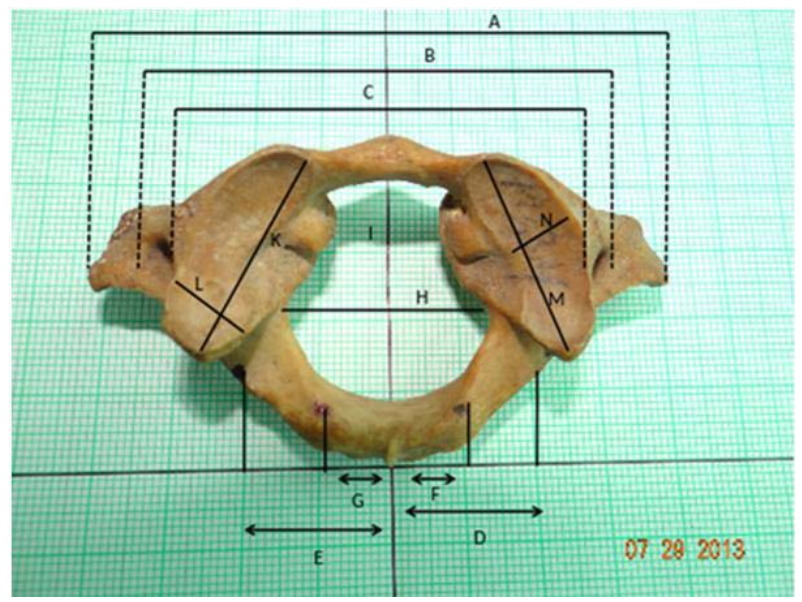

Figure 1: Different parameters studied on each atlas vertebra (A-Distance between both tips of Transverse process; BDistance between both lateral most edge of transverse foramen-Tf-Tf; C-Distance between medial edges of transverse foramen -Tf-Tf; D-Distance from midline to medial most edge of vertebral artery groove outer cortex (right) ; EDistance from midline to medial most edge of vertebral artery groove outer cortex (Left); F-Distance from midline to medial most edge of vertebral artery groove on inner cortex (Right); G-Distance from midline to medial most edge of vertebral artery groove on inner cortex (Left); H-Max transverse diameter of vertebral canal; I-AP dimension of vertebral canal -Maximum; J-AP dimension of vertebral canal -Minimum; K-superior articular facet-length-Left; L-superior articular facet-Breadth-Left; M-superior articular facet-Length-Right; $\mathrm{N}$-superior articular facet-width -Right)

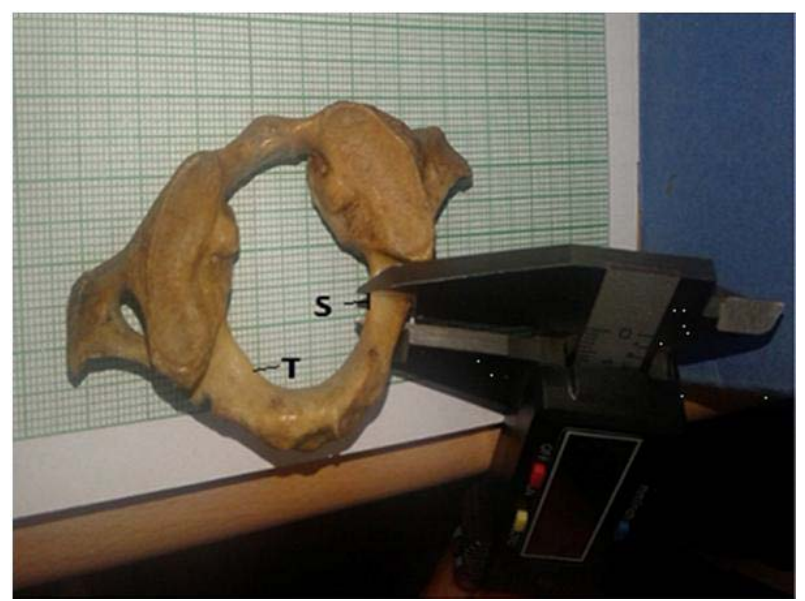

Figure 2: Different parameters studied on each atlas vertebra (S-Thickness of posterior arch at the site of vertebral artery groove-Right; T-Thickness of posterior arch at the site of vertebral artery groove-Left)

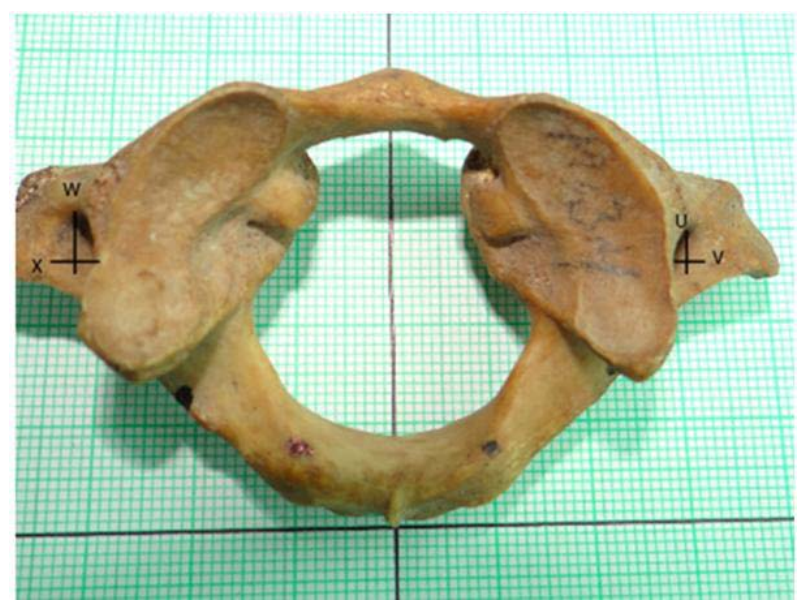

Figure 3: Different parameters studied on each atlas vertebra (U-Foramen transversarium Antero posterior diameter -Right; V-Foramen transversarium Transverse diameter -Right; WForamen transversarium Antero posterior diameter -Left; XForamen transversarium transverse diameter -Left)

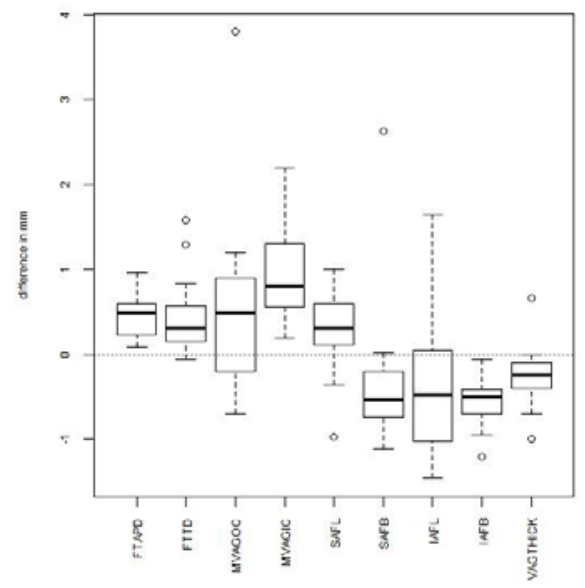

Figure 4: The boxplots for the paired difference between the right sided and left sided parameters 
Table 2: The univariate statistics for each parameter studied

\begin{tabular}{|c|c|c|c|c|c|c|c|c|}
\hline Parameter & Side & Mean & $\begin{array}{l}\text { Standard } \\
\text { Deviation }\end{array}$ & Median & Minimum & $\begin{array}{c}\text { 25th } \\
\text { percentile }\end{array}$ & $\begin{array}{c}\text { 75th } \\
\text { percentile }\end{array}$ & Maximum \\
\hline \multirow{2}{*}{$\begin{array}{l}\text { Foramen Transversarium } \\
\text { Anteroposterior Diameter }\end{array}$} & Left & 6.97 & 0.99 & 6.87 & 5.00 & 6.22 & 7.80 & 8.99 \\
\hline & Right & 7.40 & 1.13 & 7.36 & 5.49 & 6.33 & 8.33 & 9.45 \\
\hline \multirow{2}{*}{$\begin{array}{l}\text { Foramen Transversarium } \\
\text { Transverse Diameter }\end{array}$} & Left & 5.53 & 0.72 & 5.47 & 4.13 & 5.09 & 5.94 & 7.02 \\
\hline & Right & 5.91 & 1.03 & 5.80 & 4.29 & 5.26 & 6.43 & 8.60 \\
\hline \multirow{2}{*}{$\begin{array}{l}\text { Inferior Articular Facet: } \\
\text { Breadth }\end{array}$} & Left & 16.39 & 1.93 & 15.99 & 13.14 & 15.16 & 17.82 & 20.06 \\
\hline & Right & 15.84 & 1.83 & 15.38 & 12.69 & 14.61 & 17.05 & 19.95 \\
\hline \multirow[t]{2}{*}{ Inferior Articular Facet: Length } & Left & 16.67 & 1.84 & 17.09 & 12.62 & 15.68 & 17.88 & 20.36 \\
\hline & Right & 16.24 & 1.44 & 16.14 & 13.67 & 15.41 & 16.81 & 21.16 \\
\hline $\begin{array}{l}\text { Midline to medial edge } \\
\text { Vertebral Artery Groove: Inner }\end{array}$ & Left & 9.72 & 2.56 & 9.12 & 6.00 & 8.00 & 10.57 & 17.80 \\
\hline Cortex & Right & 10.73 & 2.92 & 9.80 & 7.80 & 8.70 & 12.45 & 20.00 \\
\hline $\begin{array}{l}\text { Midline to medial edge } \\
\text { Vertebral Artery Groove: Outer }\end{array}$ & Left & 24.39 & 2.06 & 24.05 & 20.90 & 23.05 & 25.88 & 29.00 \\
\hline Cortex & Right & 24.85 & 2.78 & 24.50 & 20.20 & 22.81 & 26.00 & 32.80 \\
\hline \multirow{2}{*}{$\begin{array}{l}\text { Superior Articular Facet: } \\
\text { Breadth }\end{array}$} & Left & 12.19 & 1.58 & 11.96 & 9.55 & 11.03 & 13.13 & 15.51 \\
\hline & Right & 11.82 & 1.79 & 11.15 & 9.52 & 10.73 & 12.63 & 18.14 \\
\hline \multirow{2}{*}{$\begin{array}{l}\text { Superior Articular Facet: } \\
\text { Length }\end{array}$} & Left & 21.84 & 2.11 & 22.02 & 16.68 & 20.30 & 23.28 & 25.49 \\
\hline & Right & 22.13 & 2.26 & 22.52 & 16.99 & 20.84 & 23.45 & 25.80 \\
\hline $\begin{array}{l}\text { Thickness of posterior arch at } \\
\text { the site of Vertebral Artery }\end{array}$ & Left & 4.05 & 0.88 & 3.92 & 2.70 & 3.52 & 4.39 & 6.92 \\
\hline Groove & Right & 3.79 & 1.08 & 3.68 & 1.70 & 3.05 & 4.38 & 7.58 \\
\hline
\end{tabular}

test was employed to find out whether there was a statistically significant difference between each measured parameter on the right and left side. The pvalues were adjusted for multiple comparisons by the method of Holm. The linear relationship between the different parameter was estimated by the Spearman Correlation Coefficient. All tests were carried out by the $\mathrm{R}$ statistical environment.

\section{Results}

All the parameters studied showed significant differences between the right and left sides. The anteroposterior diameter of the foramen transversarium, thetransverse diameter of the foramen transversarium, the distance from the midline to medial edge of the vertebral artery groove (inner as well as outer cortex) and the length of the superior articular facets were more on the right side as compared to the left side. The breadths as well as the length of the inferior articular facet, the breadth of the superior articular facet and the difference of posterior arch thickness at the site of vertebral artery groove were more on the left side as compared to the right side. The paired differences between the right and left side of all the above mentioned parameters were assessed by the Wilcoxon Signed Rank test and were significant for all the above parameters, even after adjustment for multiple comparisons by Holm's method. The univariate descriptive statistics of each parameter studied are given in Table 2. The univariate statistics of the paired differences, as well as the results of the Wilcoxon Signed Rank test are given in Table 3. The boxplots of the paired differences between the right and left sided parameters are given in Figure 4. There was also a significant linear association between each of the parameters studied (all the Spearman correlation coefficients between any parameter pair was more than 0.99). 
Table 3: The univariate statistics for the pair wise differences for the parameters, with the Unadjusted and Holm adjusted p-value for the Wilcoxon signed rank test

\begin{tabular}{lcccccccccc}
\hline Parameter & Mean & $\begin{array}{c}\text { Standard } \\
\text { Deviation }\end{array}$ & Median & Min & $\begin{array}{c}\text { 25th } \\
\text { percentile }\end{array}$ & $\begin{array}{c}\text { 75th } \\
\text { percentile }\end{array}$ & Max & $\begin{array}{c}\text { Unadjusted Holm adjusted } \\
\text { p-value }\end{array}$ \\
\hline p-value
\end{tabular}

FTAPDDIFF- Difference of A-P diameters of Foramen Transversarium of both sides,

TTDDIFF- Difference of Transverse diameters of Foramen Transversarium of both sides,

MVAGOCDIFF- Difference of Midline Distance of Vertebral Artery Groove on outer cortex of both sides,

MVAGICDIFF- Difference of Midline Distance of Vertebral Artery Groove on inner cortex of both sides,

SAFLDIFF- Difference of lengths of superior articular facets of both sides,

SAFBDIFF- Difference of breadth of superior articular facets of both sides,

IAFLDIFF- Difference of lengths of inferior articular facets of both sides,

IAFBDIFF- Difference of breadth of inferior articular facets of both sides,

PATHICKDIFF- Difference of posterior arch thickness at the site of vertebral artery groove of both side

\section{Discussion}

In all the parameters measured, there were small but statistically significant differences between the right and left side of the atlas. several authors reported asymmetry of the shape and surface area of the superior articular facets of the atlas $(3,9,17,19,20)$. We found the thickness of the posterior arch at the site of vertebral artery groove is greater on left side; while anteroposterior, transverse diameters of foramen transversarium and the distance from the midline to the medial most edge of vertebral artery groove on outer and inner cortex are larger on right side (Tables/Fig. 3 and 4).We also found asymmetry in the length and breadth of superior articular facets as well in the inferior articular facets of atlas. Both the dimensions i.e. length and breadth, in the inferior articular facets and breadth in the superior articular facets are larger on the left (Table/Fig. 3 and 4).

Differences between the superior articular facets on the different sides were reported by earlier researchers $(9,19,21)$, as were differences in the inferior articular facet (21) and foramen transversarium (19). In addition we have also found a significant difference between the right and left sides in the thickness of the posterior arch at the site of vertebral artery groove and in the distance from the midline to the medial most edge of the vertebral artery groove for the outer and inner cortex. Therefore, we recorded asymmetry in almost all the measurable components of atlas, which appears to be a rule rather than the exception.

This asymmetry can be explained on the basis of "Handedness" of the population surveyed. Righthandedness is common in general population (22). A person of particular handedness uses his limbs and musculature of the respective side (right or left) more frequently than the opposite. Because of greater use, there will be comparatively greater requirement of energy, energy substrate and consequently greater need of blood supply. This may lead to a larger calibre of the artery concerned e.g. vertebral artery, which ultimately will lead to larger dimensions of the corresponding foramen transversarium and the less thickness of posterior arch at the site of the vertebral artery groove as compared to the other. Though we did not have any information regarding the handedness of the cadavers from whom these vertebrae were harvested, but based on the prevalence of the handedness in general population (22), it is likely that most of the vertebrae belonged to right handed individuals. So, we can hypothesise 'the handedness influences the intra-osteal asymmetry in a characteristically, distinct manner'. However, confirmation of this hypothesis warrants further research.

As far as the asymmetry of SAF and IAF are concerned they are also substantiated by the above hypothesis. Whenever a right handed person uses his right upper 
limb for lifting a weight, his head is tilted to the left side to maintain the balance. In these situations, left SAF and IAF of atlas are subjected to a greater force compared to the right. To cope up with this force, the dimensions i.e. length and breadth of the SAF and IAF and consequently their surface area become larger.

All the differences that we got were statistically significant. There was also a significant linear association between each of the parameters studied (all the Spearman correlation coefficients between any parameter pair was more than 0.99). These asymmetries may be of help to those choosing the different sizes of the implants to be used and the lengths of the incisions that are to be given in the cranio-vertebral region. This may also be of use to those concerned with manipulative and physical therapy.

\section{Conclusion}

All the differences that we got were statistically significant. There was also a significant linear association between each of the parameters studied (all the Spearman correlation coefficients between any parameter pair was more than 0.99). These asymmetries may be of help to those choosing the different sizes of the implants to be used and the lengths of the incisions that are to be given in the cranio-vertebral region. This may also be of use to those concerned with manipulative and physical therapy. Furthermore, these differences may be explained by the handedness of an individual, which influences the intraosteal asymmetry in a characteristically distinct manner, which needs to be confirmed or refuted in a further study.

\section{References}

1. Gluf WM, Schmidt MH, Apfelbaum RI. Atlantoaxial transarticular screw fixation: a review of surgical indications, fusion rate, complications, and lessons learned in 191 adult patients. J Neurosurg Spine 2005; 2(2): 155-63.

2. Behari S, Bhargava V, Nayak S, et al. Congenital reducible atlantoaxial dislocation: classification and surgical considerations. Acta Neurochir (Wien) 2002; 144(11): 1165-77.

3. Gottlieb MS. Absence of symmetry in superior articular facets on the first cervical vertebra in humans: Implication for diagnosis and treatment. J Manipulative Physiol Ther 1994; 17(5): 314-20.

4. Nansel DD, Peneff AL, Jansen RD, Cooperstein R. Interexamier concordance in detecting joint-play asymmetries in the cervical spines of otherwise asymptomatic subjects. J Manipulative Physiol Ther 1989; 12(6): 428-33.

5. Fitz-Ritson D. Assessment of cervicogenic vertigo. J Manipulative Physiol Ther 1991; 14(6): 193-8.

6. Schafer RC, Faye LJ Motion palpation and chiropractic technic, 2nd ed. Huntington Beach, CA: Motion Palpation Institute, 1990, pp-426.

7. Grieve GP. (Ed). Modern manual therapy of the vertebral column. Churchill Livingstone, Edinburgh, 1986, pp-330-335.

8. Grieve GP. Applied anatomy-regional. In: Grieve GP (ed). Common Vertebral Joint Problems. Churchill Livingstone, Edinburgh, 1988, Ch 1, pp $1-77$.

9. Singh S. Variations of the superior articular facets of atlas vertebrare. J Anat 1965; 99(Pt 3): 565-71.

10. Mysorekar VR, Nandekar AN. Surface area of the atlanto-occipital articulations. Acta Anat (Basel) 1986; 126(4): 223-5.

11. Tulsi RS. Some specific anatiomical features of the atlas and axis: dens, epitransverse process and articular facets. Aust NZ Surg 1978; 48(5): 570-4.

12. Tillmann B, Lorenz R. The stress at the human atlanto-occipital joint. I. the development of the occipital condyle. Anat Embryol (Berl) 1978; 153(3): 269-77.

13. Febbo TA, Morrison R, Valente R. Asymmetry of the occipital Condyles a computer-assisted analysis. J Manipulative Physiol Ther 1992; 15(9): 565-69.

14. Febbo T, Morrison R, Bartlett P. A preliminary study of occipital condyle asymmetry in dried specimens. Chiropr Techn 1990; 2(2): 49-52.

15. Guidotti A. Morphomertical considerations on occipital condyles. Anthropol Anz 1984; 42(2): 117-9.

16. Howe JW. Some considerations in spinal X-ray interpretations. J Chin Chiro 1971; 1: 75-96.

17. Pei-Feng J, Li-Ping W, Ji-Hong F, Yi-Kai L, Manas D. Morphological asymmetry of the atlas and its clinical implications. J Manipulative Physiol Ther 2011; 34(7): 463-7. 
18. Ross JK, Bereznick DE, McGill SM. Atlas-axis facet asymmetry. Implications in manual palpation. Spine (Phila Pa 1976) 1999; 24(12): 1203-9.

19. Van Roy P, Caboor D, De Boelpaep S, Barbaix E, Clarys JP. Left-right asymmetries and other common anatomical variants of the first cervical vertebra. Man Ther 1997; 2(1): 24-36.

20. Gottlieb MS. Absence of symmetry in superior articular facets on the first cervical vertebra in humans: implications for diagnosis and treatment. J Manipulative Physiol Ther 1994; 17(5): 314-20.
21. Meseke CA, Duray SM, Brillon SR. Principal components analysis of the atlas vertebra. J Manipulative Physiol Ther 2008; 31(3): 212-6.

22. Barrett KE, Barman SM, Boitano S, Brooks HL. Ganong's review of medical physiology. $23^{\text {rd }}$ Edition. New York: McGraw Hill/Lange. 2010, pp-295-96. 